\title{
Levantamento de medidas de prevenção a doenças ocupacionais
}

\author{
Prevention measures' survey of occupational diseases \\ Encuesta de medidas de prevención de enfermedades profesionales \\ Erika Tamy Almeida TAKEUTI ${ }^{1}$ \\ Tânia Adas SALIBA2
}

${ }^{I}$ Graduanda em Odontologia, Faculdade de Odontologia, UNESP Univ. Estadual Paulista, 16052-280 Araçatuba-SP, Brasil

${ }^{2}$ Professora Associada, Departamento de Odontologia Preventiva e Restauradora, Faculdade de Odontologia, UNESP Univ. Estadual Paulista, 16015-050 Araçatuba - SP, Brasil

\section{Resumo}

O Cirurgião-Dentista está exposto à riscos ocupacionais em sua rotina profissional, que podem vir a causar danos em sua saúde, acidentes no ambiente de trabalho ou doenças ocupacionais, que vêm sendo retratadas na literatura desde o século XVIII. Os principais riscos estão relacionados a agentes biológicos, físicos, químicos, mecânicos e ergonômicos, que podem gerar escoliose, cifoescoliose e diversas Lesões por Esforço Repetitivo/Distúrbios Osteomusculares Relacionados ao Trabalho por meio de posturas inadequadas. O objetivo deste trabalho foi buscar na literatura científica os principais riscos aos quais o Cirurgião-Dentista se encontra exposto, analisar as medidas preventivas para que os profissionais da área possam ter mais conforto e segurança em um ambiente de trabalho e melhoria das condições. Concluímos que os Equipamentos de Proteção Individual (EPIs) são os melhores meios de evitar os riscos ocupacionais e, ao seguir rigorosamente todos os procedimentos destinados a manter a cadeia asséptica e promover a prática da ginástica laboral ao final do expediente, diminui os riscos laborais.

Descritores: Odontologia; Doenças Profissionais; Contenção de Riscos Biológicos.

\section{Abstract}

Dental Surgeons are exposed to occupational risks in his professional routine, which can cause damage to their health, accidents in the workplace or occupational diseases, which have been portrayed in the literature since the 18th century. The main risks are related to biological, physical, chemical, mechanical and ergonomic agents, which can generate scoliosis, kyphoscoliosis and various Repetitive Strain Injuries / Work-related Musculoskeletal Disorders through inappropriate postures. The objective of this work was to search the main risks to which the Dental Surgeon is exposed in the scientific literature, to analyze preventive measures so that professionals in the area can have more comfort and safety in a work environment and improve conditions. We conclude that Personal Protective Equipment (PPE) is the best means of avoiding occupational risks and, by strictly following all procedures aimed at maintaining the aseptic chain and promoting the practice of workplace gymnastics at the end of the day, it reduces occupational risks.

Descriptors: Dentistry; Occupational Diseases; Containment of Biohazards.

\section{Resumen}

El cirujano dental está expuesto a riesgos laborales en su rutina profesional, lo que puede causar daños a su salud, accidentes en el lugar de trabajo o enfermedades profesionales, que han sido retratadas en la literatura desde el siglo XVIII. Los principales riesgos están relacionados con agentes biológicos, físicos, químicos, mecánicos y ergonómicos, que pueden generar escoliosis, cifoscoliosis y diversas lesiones por esfuerzo repetitivo / trastornos musculoesqueléticos relacionados con el trabajo a través de posturas inapropiadas. El objetivo de este trabajo fue buscar los principales riesgos a los que está expuesto el cirujano dental en la literatura científica, analizar medidas preventivas para que los profesionales en el área puedan tener más comodidad y seguridad en un ambiente de trabajo y mejorar las condiciones. Concluimos que el equipo de protección personal (EPP) es el mejor medio para evitar riesgos laborales y, siguiendo estrictamente todos los procedimientos destinados a mantener la cadena aséptica y promover la práctica de la gimnasia en el lugar de trabajo al final del día, reduce los riesgos laborales.

Descriptores: Odontología; Enfermedades Profesionales; Contención de Riesgos Biológicos

\section{INTRODUÇÃO}

A Saúde do Trabalhador no Brasil atua nas relações do trabalho e saúde-doença da classe operária industrial. É um campo da saúde pública que visa promover e proteger a saúde de pessoas no exercício do trabalho, sendo necessária a atuação multi e interdisciplinar com profissionais especializados, buscando preservação e promoção de saúde. A preocupação com os riscos à saúde relacionados à atividade profissional do trabalhador fez com que fossem criadas normas regulamentadoras ${ }^{1,2}$. Várias determinações voltadas para profissionais da área da saúde estão contidas na NR-32, aprovada pela Portaria no 485/2005 do Ministério do Trabalho e Emprego. De acordo com a Portaria $n^{\circ} 3.214 / 1978$ na NR-6 do Ministério do Trabalho e Emprego, no caso de agentes insalubres químicos e físicos, equipamentos de proteção individual (EPI), assim como equipamentos de proteção coletiva e controle na fonte, devem ser adotados ${ }^{3}$.

$\mathrm{Na}$ Odontologia, as considerações relacionadas às doenças ocupacionais e patológicas provenientes da má postura ergonômica devem ser investigadas, pois é alarmante a prevalência de profissionais com Distúrbios Osteomusculares Relacionadas ao Trabalho (DORT) e Lesões por Esforço Repetitivo (LER) ${ }^{4}$.Tais distúrbios afetam principalmente a região do pescoço, da cintura escapular e dos membros superiores e ocupam o segundo lugar das causas de doenças entre os trabalhadores, sendo que grande parte das aposentadorias por invalidez, conforme disposto no art. 42 da Lei $n^{\circ}$ 8213/1991, é decorrente dessas patologias 5 .

Dos profissionais de Odontologia, $75 \%$ estão expostos ao risco de desenvolvimento de distúrbios osteomusculares relacionados ao trabalho. As LER e DORT estão associadas a múltiplos fatores de risco: físicos, psicossociais, organização do trabalho e sociocultural. São ocasionadas pela má postura no desempenho das funções durante a longa jornada de trabalho, além disso, movimentos recorrentes e repetitivos e a falta de intervalos também agravam a situação. A sintomatologia dolorosa pode se desenvolver ainda no período de graduação e progredir durante a vida profissional, caso medidas corretivas ou preventivas não sejam implementadas ${ }^{4,5}$. 
Com o preconceito da AIDS (HIV) e a transmissão da hepatite $\mathrm{B}$ e C, Cirurgiões-Dentistas passaram a ter uma preocupação maior durante $\mathrm{o}$ tratamento odontológico, as hepatites virais representam risco ocupacional, devido à exposição aos fluidos biológicos. É necessária a adoção de medidas de precaução e conhecimento dos aspectos relacionados a patogenia e transmissão das hepatites virais. Atualmente, há sete tipos de hepatites virais (A, B, C, D, E, F e G). É importante conhecer as hepatites, em especial as $\mathrm{B}$ e $\mathrm{C}$, devido à variedade de apresentações clínicas, altos riscos de morbidade e mortalidade e de transmissão durante os procedimentos ${ }^{6,7}$.

A aplicação de princípios de biossegurança é uma maneira eficaz de se garantir segurança, o alto desempenho, a salubridade, além de motivação e satisfação no trabalho odontológico ${ }^{8}$. A biossegurança na prática odontológica constitui um conjunto de medidas empregadas com o propósito de proteger a equipe e o paciente no ambiente clínico. Para um controle de infecção efetivo deve-se seguir um conjunto de medidas técnicas básicas, que incluem anamnese, equipamentos de proteção individual (EPIs) procedimento de lavagem de mãos, preparo, esterilização e desinfecção do instrumental e uma correta ergonomia ${ }^{9}$.

Com base no exposto o objetivo deste trabalho foi buscar evidências publicadas na literatura científica sobre os principais riscos ocupacionais aos quais se encontra exposto o Cirurgião-Dentista no exercício de sua profissão, analisar medidas preventivas para que os profissionais da área possam ter mais conforto e um ambiente de trabalho seguro, visando a melhoria de suas condições laborais e produtividade mais expressiva em seu cotidiano. Como objetivos específicos buscou-se identificar os riscos ocupacionais aos quais os Cirurgiões-Dentistas encontram-se expostos no exercício da profissão e, analisar as medidas preventivas para obtenção de conforto, segurança, melhoria das condições laborais e aumento da produtividade.

\section{MATERIAL E MÉTODO}

Foi realizada uma revisão da literatura para investigar os riscos ocupacionais aos quais acadêmicos e profissionais da Odontologia estão expostos. Foram pesquisados trabalhos científicos nacionais e internacionais no período de 2009 a 2020, selecionados 21 trabalhos, e excluídos 46. As pesquisas foram realizadas nas bases de dados MEDLINE, Scielo, PubMed, com enfoque nos descritores "Odontologia", "Doenças profissionais" e "Contenção de riscos biológicos" (Figura 1)

\section{RESULTADOS}

Os resultados foram organizados no Quadro 1 , que apresenta os principais estudos encontrados.

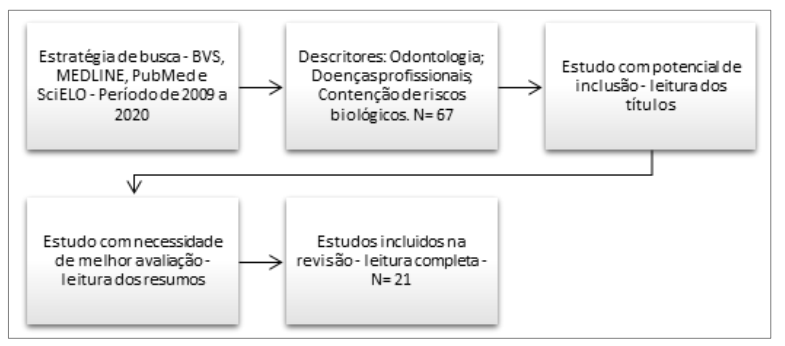

Figura1: Fluxograma da revisão da literatura

\begin{tabular}{|c|c|c|}
\hline Título & Autores/Ano & Conclusões \\
\hline $\begin{array}{lr}\text { Ergonomia } & \text { e } \\
\text { desconforto físico: } \\
\text { uma abordagem } \\
\text { entre } & \text { os } \\
\text { acadêmicos } & \text { em } \\
\text { odontologia } & \end{array}$ & $\begin{array}{l}\text { Garbin et al. }{ }^{2} \\
2018\end{array}$ & $\begin{array}{l}\text { Para prevenção do desconforto na atividade } \\
\text { clínica, é necessário que o profissional, } \\
\text { desde a graduaçấo, realize ginástica laboral } \\
\text { ao fim de cada dia de trabalho, } \\
\text { acompanhada de orientações sobre } \\
\text { posturas adequadas e avaliaçôes } \\
\text { ergonômicas. A prática da ginástica quando } \\
\text { realizada corretamente, auxilia quanto a } \\
\text { redução de dores, fadiga muscular, estresse } \\
\text { e ocorrência de acidentes e doenças } \\
\text { ocupacionais. }\end{array}$ \\
\hline $\begin{array}{l}\text { Condutas do } \\
\text { cirurgião-dentista } \\
\text { frente a acidentes } \\
\text { biológicos }\end{array}$ & $\begin{array}{l}\text { Bragança et al. }{ }^{11} \\
2010\end{array}$ & 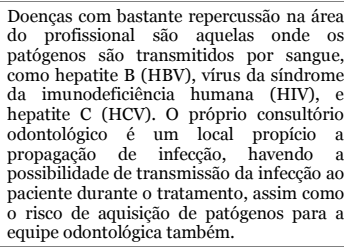 \\
\hline $\begin{array}{l}\text { Coronavirus } \\
\text { Disease } \\
\text { (COVID-19): } \\
\text { implications for } \\
\text { clinical dental } \\
\text { care. }\end{array}$ & $\begin{array}{l}\text { Ather et al. }{ }^{15} \\
2020\end{array}$ & $\begin{array}{l}\text { Deve-se evitar o atendimento, porém em } \\
\text { caso de emergência, usar enxaguante bucal } \\
\text { no pré-procedimento com peróxido de } \\
\text { hidrogênio o,5-1\%, dispositivos } \\
\text { descartáveis, radiografias devem ser } \\
\text { extraorais, fazer uso de dique de borracha } \\
\text { para minimizar a geração de respingos e } \\
\text { evitar operações que possam produzir } \\
\text { gotículas e aerossóis. }\end{array}$ \\
\hline $\begin{array}{lr}\text { Normas } & \text { e } \\
\text { diretrizes } & \\
\text { ergonômicas } & \text { em } \\
\text { odontologia: } & \text { o } \\
\text { caminho para a } \\
\text { adoção de } & \text { uma } \\
\text { postura } & \text { de } \\
\text { trabalho saudável. }\end{array}$ & $\begin{array}{l}\text { Garbin et al. }{ }^{18} \\
2009\end{array}$ & 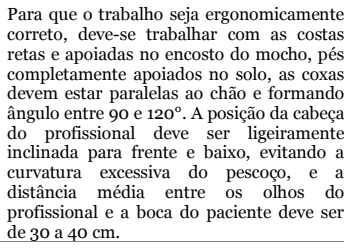 \\
\hline 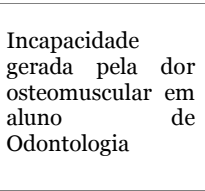 & $\begin{array}{l}\text { Santos et al. }{ }^{19} \\
2018\end{array}$ & $\begin{array}{l}\text { Os profissionais da área de Odontologia são } \\
\text { os mais vulneráveis ao desenvolvimento de } \\
\text { doenças osteomusculares, por isso devem } \\
\text { estar mais atentos aos primeiros sinais de } \\
\text { alteração, para que possam prevenir } \\
\text { tratá-las quanto antes, evitando o } \\
\text { comprometimento de estruturas } \\
\text { anatômicas que são importantes para a } \\
\text { profissão. }\end{array}$ \\
\hline
\end{tabular}

Quadro 1. Principais artigos dos artigos incluídos na revisão de literatura.

\section{REVISÃO DA LITERATURA}

A saúde do trabalhador é um conjunto de atividades destinado à promoção e proteção da saúde dos mesmos, por meio de ações de vigilância sanitária e epidemiológica, visando a reabilitação da saúde daqueles que foram expostos aos riscos e agravos provenientes das condições de trabalho'.

Os trabalhadores da área da saúde estão expostos a um processo gerador de doenças profissionais, as quais englobam variados riscos e fatores predisponentes ao desequilíbrio biopsicossocial. É importante salientar que esses riscos e fatores muitas vezes não são encarados com a seriedade que deveriam, gerando agravos à saúde 2 .

Risco ocupacional

O risco ocupacional está presente de várias maneiras na rotina de trabalho do Cirurgião-Dentista. São considerados riscos ocupacionais a possibilidade de perda ou danos à saúde e a probabilidade de que isto ocorra. Os mais frequentes a que estão sujeitos os 
profissionais que atuam em assistência odontológica são os físicos, químicos, ergonômicos, mecânicos ou de acidente e biológicos ${ }^{10}$.

A maior parte dos Cirurgiões-Dentistas relatam já terem sofrido danos gerados em decorrência dos riscos ocupacionais, conforme mostram trabalhos realizados por Garbin et al. ${ }^{5}$, onde foi documentado que mais de $80 \%$ dos pesquisados sentem dores ou já tiveram doenças ocupacionais.

\section{○ Riscos biológicos}

Exposições a materiais biológicos contaminados são um sério risco aos profissionais da área da saúde em seus locais de trabalho. Considerase como risco biológico a possibilidade de ocorrência de um evento devido a presença de um agente biológico. Acidentes envolvendo fluidos orgânicos são os que são mais relatados ${ }^{11}$.

O consultório odontológico é um ambiente considerado de alto risco, pois coloca o CirurgiãoDentista em contato direto com secreções e fluídos dos pacientes, como sangue e saliva, que possui bactérias, vírus e fungos, que contribuem para o aumento da possibilidade de infecções cruzadas, principalmente pelos aerossóis. Os aerossóis são uma suspensão de micropartículas sólidas ou líquidas, invisíveis, produzidas durante $\mathrm{o}$ tratamento odontológico através do uso dos motores de alta e baixa rotação, seringas tríplices e raspadores ultrassônicos, sendo que penetram no organismo através das vias aérea e ocular ${ }^{11,12}$.

$\mathrm{O}$ herpes vírus simples representa a doença viral mais comum no homem, e pode permanecer em latência, além de apresentar manifestações clínicas e subclínicas em fases intercaladas. É importante que o Cirurgião-Dentista tenha conhecimento e saiba reconhecer as manifestações bucais do herpes, uma vez que é normal o aparecimento de pacientes com sintomatologia clínica. Não é recomendado o tratamento de tais pacientes, salvo urgência, devido ao risco da auto inoculação do vírus, mesmo que com uso de EPI, além do desconforto para o paciente ${ }^{1,2}$.

Oliveira e Ferreira ${ }^{4}$ relataram que o risco biológico foi o mais citado pelos acadêmicos. Em seu estudo, em relação a aplicação de EPI constatou-se que não é rotineiro o uso de todos os equipamentos, sendo, em ordem, os mais utilizados: luvas (23\%), gorro $(21 \%)$, e máscara (17\%). Constataram, também, que a imunização contra o HBV é indispensável ao profissional da saúde. Receber as 3 doses da vacina não significa, necessariamente, que estará imunizado, pois há relatos de não ocorrência da imunização após a $3^{\text {a }}$ dose, sendo necessária a realização do teste anti-HBs.

Um dos riscos ocupacionais biológicos mais conhecidos envolvendo os Cirurgiões-Dentistas é o HBV. Dado a sua estabilidade no meio ambiente ser alta e a capacidade de sobreviver em pequenas quantidades de sangue seco, pouco sangue ou secreções o contendo, já são suficientes para transmitir infecção ${ }^{10}$.

O constante uso de instrumentos críticos na Odontologia, aqueles que penetram nos tecidos e atingem o sistema vascular, e os semicríticos, que entram em contato com a pele íntegra ou mucosa, sangue e saliva, bem como o ritmo de trabalho que leva ao desgaste do trabalhador e consequentemente interfere na sua atenção em relação ao manuseio dos instrumentais e o posicionamento paciente/profissional muito próximo são fatores que contribuem para risco de exposição ao agente biológico $^{11,12}$.

Uma medida recomendada pela American

Dental Association (ADA) para diminuir a contaminação é que os equipamentos devam ser acionados no início dos trabalhos, se livrando dos micro-organismos que se acumularam entre os pacientes ${ }^{1,11 .}$

- COVID-19

COVID-19, do inglês Coronavirus Disease 2019, é uma doença infeciosa causada pelo corona vírus da síndrome respiratória aguda grave 2 (SARSCoV-2). No dia 11 de março de 2020 a Organização Mundial da Saúde declarou a doença como pandêmica. Os sintomas incluem tosse seca, febre, fadiga, doença respiratória aguda, com casos graves que levam a pneumonia, insuficiência renal e até morte, além de sintomas atípicos como dor muscular, confusão, dor de cabeça, diarreia e vômito. O período de incubação foi estimado na média de 5 a 6 dias, mas há evidências que pode durar até 14 dias, que se tornou a duração comumente adotada para observação médica e quarentena de pessoas potencialmente expostas ${ }^{14,15}$.

No que tange a Odontologia, um estudo realizado por Guo et al. ${ }^{13}$ em Beijing na China, foram entrevistados 2537 pacientes sendo 1242 mulheres e 1295 homens, notou-se que a pandemia teve influência no uso dos serviços odontológicos, com $38 \%$ menos pacientes visitando o centro de emergência no início da pandemia em comparação a um mês antes (970 versus 1570). Aqueles que ainda buscaram atendimento, o principal motivo das consultas de emergência foram as lesões pulpares ou periapicais, representando 44,7\%, seguidas de celulite ou abscesso com $14,2 \%$ e trauma $12,8 \%$. Enquanto o número total de pacientes tenha diminuído devido ao medo do COVID-19, os tipos de queixas dentários mudaram significativamente, sendo que a proporção de infecções dentárias e orais aumentou de $51,0 \%$ do pré-COVID-19 para $71,9 \%$ durante o COVID-19 e o trauma dentário diminuiu de $14,2 \%$ para $10,5 \%{ }^{13}$.

A infecção pode ocorrer diretamente entre paciente e profissional ou pelos materiais usados, que podem ser contaminados com vários microrganismos patogênicos após o uso ou ao ficar exposto em um 
ambiente contaminado, que pode levar a infecção cruzada. Dadas as características únicas dos procedimentos dentários onde um grande número de gotículas e aerossóis são gerados, as medidas padrão de proteção no trabalho clínico diário não são eficazes o suficiente para impedir a propagação do COVID-19, principalmente quando os pacientes estão no período de incubação ou não sabem que estão infectados ${ }^{13,14}$.

Algumas cepas de vírus foram encontradas na saliva 29 dias após a infecção, assim, a saliva é uma plataforma não invasiva para diferenciar biomarcadores, podendo fornecer um diagnóstico rápido, conveniente e econômico para a detecção da infecção, tornando indispensável amplificar as investigações da COVID-19 em fluídos orais para encontrar estratégias eficazes de prevenção, principalmente para os Cirurgiões-Dentistas que realizam procedimentos que geram aerossóis ${ }^{14}$.

Recomendações específicas para tratamento dentário incluem que pacientes febris ou com outros sintomas não devam se apresentar nas clínicas. Com base na avaliação médica, o profissional pode avaliar a gravidade da condição dentária e decidir adiar o atendimento odontológico caso necessário. Certos casos, como trauma dentoalveolar e infecção do espaço fascial, justificam intervenção odontológica de emergência. No caso de fornecer atendimento odontológico a casos suspeitos ou confirmados de infecção por COVID-19, as recomendações para prática odontológica devem incluir a orientação sobre prevenção e controle de infecção quando houver suspeita de infecção por COVID-19. Deve-se seguir as precauções padrão, incluindo o uso apropriado de equipamentos de proteção individual e práticas de higiene das mãos; usar enxaguante bucal no préprocedimento com iodopovidona a $0,2 \%$ ou com peróxido de hidrogênio $0,5-1 \%$; uso de dispositivos descartáveis como espelho bucal, seringas e manguito de pressão arterial para evitar contaminação cruzada; radiografias devem ser extraorais (radiografia panorâmica ou tomografia computadorizada de feixe cônico) pois não estimulam a secreção de saliva e tosse como as intraorais, e quando a imagem intraoral é obrigatória, os sensores devem ter barreira dupla para evitar perfuração e contaminação cruzada; fazer uso do dique de borracha para minimizar a geração de respingos e minimizar ao máximo ou evitar operações que possam produzir gotículas ou aerossóis, como o uso de instrumentos ultrassônicos, peças de mão de alta velocidade e seringa tríplice ${ }^{14,15}$.

\section{- Riscos químicos}

De acordo com a Norma Regulamentadora número 9 (NR 9) do Ministério do Trabalho e Emprego, os "agentes químicos são as substâncias, compostos ou produtos que possam penetrar no organismo pela via respiratória, nas formas de poeiras, fumos, névoas, neblinas, gases ou vapores, ou que, pela natureza da atividade de exposição, possam ter contato ou ser absorvidos pelo organismo através da pele ou por ingestão"16. Vale lembrar que nem sempre a exposição resulta em prejuízo à saúde, pois dependem de vários fatores além da suscetibilidade individual, como a frequência e duração da exposição, tipo e concentração do agente, práticas e hábitos laborais ${ }^{17}$.

Segurança química é a prevenção dos efeitos adversos, para o ser humano e o meio ambiente, decorrentes da produção, armazenagem, transporte, manuseio, uso e descarte de produtos químicos ${ }^{2}$.

O mercúrio, que também é chamado de "perigoso silencioso" pois uma vez absorvido permanece no organismo a vida toda, é um metal líquido e altamente volátil, que em temperaturas por volta de $20{ }^{\circ} \mathrm{C}$ e em locais com pouca ventilação fazem com que ele tenha pressão de vapor suficiente para produzir altas concentrações no ar. Sua principal via de penetração no organismo é respiratória, e deposita-se em órgãos como os rins, tireoide, sistema nervoso central e glândulas salivares ${ }^{8,10}$.

Está presente no dia a dia do CirurgiãoDentista na forma de ligas com prata, cobre, zinco ou estranho, na realização de restaurações. Além disso, há outra forma de intoxicação mercurial: via estufas e autoclaves no mesmo ambiente onde amálgama é manipulado, já que o mercúrio, como dito anteriormente, nessas condições volatiliza-se rapidamente ${ }^{1,8}$. São possíveis fontes de exposição da equipe odontológica e pacientes ao mercúrio: derrubar acidentalmente o mesmo, remoção inadequada de excesso, troca de restaurações de amálgama a seco com o uso da alta rotação, além de outros tantos fatores como a existência de orifícios no piso, fontes de calor próximas ao mercúrio, excessos nas cuspideiras ${ }^{8,10}$.

No Brasil, o risco de contaminação ocupacional por mercúrio é sério, uma vez que não existe um sistema adequado de monitoração e controle dos vapores de mercúrio no local de trabalho. Os profissionais de órgãos públicos devem redobrar a atenção, pois o amálgama é muito utilizado pelo mesmo ${ }^{3,10}$.

\section{- Riscos Físicos}

Os riscos físicos segundo Moura et al. ${ }^{10}$ são os provocados por energia. São exemplos: equipamentos que geram calor, pressões anormais, material radioativo, ruído, fotoativador, autoclave e radiação ultravioleta, não ionizante e ionizante ${ }^{12}$. Eles representam a troca de energia entre o ambiente de trabalho e o trabalhador em valor superior àquele que o organismo pode suportar, assim gerando doença ocupacional ${ }^{10}$.

○ Ruído

A exposição a ruídos, provocados pelas canetas de alta e baixa rotação, sugadores de saliva e compressores de ar no ambiente de trabalho pode 
afetar o Cirurgião-Dentista física e psicologicamente, resultando na diminuição de seu rendimento profissional e desagaste da saúde ${ }^{1}$.

$\mathrm{O}$ ruído em alta intensidade e em excesso pode ser relacionado ao estresse e provocar diminuição em seu rendimento laboral. Seus efeitos nocivos podem acarretar comprometimento mental, social e físico no profissional, podendo levar a Perda Auditiva Induzida por Ruído (PAIR) $)^{1,2}$.

Garbin et al. ${ }^{9}$ avaliaram o nível de ruído em uma clínica odontológica da Faculdade de Odontologia de Araçatuba (UNESP). A média de ruído documentada foi de $76 \mathrm{~dB}$, e o valor mínimo e máximo produzidos foram 70 e $83,4 \mathrm{~dB}$, respectivamente. Com os resultados pode-se confirmar que o Cirurgião-Dentista está exposto a estresse, pois os valores sugerem incômodo 9 .

Para minimizar os riscos, deve-se adquirir equipamentos menos ruidosos, ficar atento à manutenção destes isolar o compressor de ar com caixa acústica, proteger paredes contra reverberação sonora e fazer o uso de protetores auriculares ${ }^{9}$.

\section{- Iluminação}

A iluminação deve ser adequada a fim de evitar fadiga visual, que acarreta cefaleia e até problemas crônicos nos olhos. A iluminação natural e artificial nos consultórios facilita o uso dos instrumentos e na seleção de cores de material dentário ${ }^{1,8}$.

Presbiopia é uma deficiência visual que afeta Cirurgiões-Dentistas após anos de exercício da profissão, levando à dificuldade de focar objetos a curta distância. A curto prazo, afeta quanto a queda do rendimento e falta de atenção devido ao cansaço, bem como diminui a qualidade do serviço ${ }^{3}$.

A luz do fotoativador, embora mais segura que a ultravioleta, é ofensiva, e se usada demasiadamente pode causar injúria na retina ${ }^{1}$.

Como prevenção deve-se usar óculos de proteção durante os procedimentos odontológicos e o manuseio de equipamentos que possuem luz alógena ${ }^{1}$.

\section{○ Radiação}

Uma pequena quantidade de radiação, como o caso dos aparelhos de raio $\mathrm{X}$ odontológico, não é suficiente para provocar manifestação imediata em dose única, mas provocará efeitos deletérios no organismo $^{10}$.

Os Cirurgiões-Dentistas têm como responsabilidade profissional minimizar os riscos associados à radiação, protegendo de exposições desnecessárias usando equipamentos de proteção com chumbo e técnicas seguras como a do paralelismo, evitando repetições, além de distância mínima de $1,8 \mathrm{~m}$ do cabeçote do aparelho de raios $\mathrm{X}$ e não segurar o filme na boca do paciente ${ }^{1,10}$.

- Risco mecânico

$$
\text { Risco mecânico é a exposição dos }
$$

profissionais a agentes mecânicos ou que causem acidentes. São relacionados ao espaço físico ou materiais. Os mais frequentes são instrumentais defeituosos ou impróprios para procedimento, espaço físico inadequado, edificação com defeitos e ausência de $\mathrm{EPI}^{1}$.

Os riscos relacionados à falta de higiene $\mathrm{e}$ conforto estão ligados a banheiros insuficientes, em muitos casos únicos e não separados por gênero, falta de produtos de higiene pessoal, não fornecimento de uniformes, falta de local adequado para descanso, lanches e refeições, entre outros. Como procedimentos de prevenção a riscos mecânicos a ANVISA sugere que seja proporcionado à equipe condições de higiene, conforto e salubridade no ambiente de trabalho, seguindo a NR $24^{3}$, e quanto ao risco mecânico estão o uso de materiais e medicamentos registrados na ANVISA, bem como instrumentais de qualidade e em condições de trabalho, aquisição de equipamentos registrados no Ministério da Saúde ergonomicamente testados, instalação de extintores de incêndio, manutenção preventiva periódica da estrutura do consultório ${ }^{1}$.

\section{○ Risco ergonômico}

Os riscos ergonômicos são relacionados à má postura, falta de planejamento, bem como de auxiliar e sua capacitação, excessivo ritmo de trabalho e seu ato repetitivo, exigências de produtividade exageradas, entre outros. Então, para minimizar o risco ergonômico deve-se trabalhar com um auxiliar capacitado, realizar planejamento diário para uma melhor organização do trabalho, frequentemente fazer atividades físicas como alongamento entre atendimentos e zelar pela equipe odontológica ${ }^{18}$.

Como forma de ajudar os profissionais quanto aos riscos ocupacionais, a ergonomia surgiu durante a $2^{\mathrm{a}}$ Guerra Mundial, quando pela primeira vez, foi aplicada de forma coordenada e sistemática. É um conjunto de saberes multidisciplinares para organização da atividade laborativa com o objetivo de estabelecer um ambiente saudável, confortável e seguro, prevenindo agravos à saúde e contribuindo para o aumento da produtividade, diminuição do estresse físico e cognitivo, além de prevenir doenças relacionadas à prática odontológica ${ }^{9,19}$. A ergonomia na Odontologia tem como objetivo a racionalização do trabalho visando sua simplificação, a prevenção da fadiga e o maior conforto tanto para o profissional quanto para o paciente. O Cirurgião-Dentista é um profissional vulnerável a problemas ocupacionais, devido aos riscos relacionados às más posturas durante sua atividade laboral, rotina de trabalho e esforços repetitivos, resultando em degeneração dos discos intervertebrais devido à sua pressão, varizes, cefaleia e fadiga ${ }^{18,19}$.

Desde a graduação é fundamental adotar protocolos e princípios ergonômicos durante o atendimento ao paciente. $\mathrm{O}$ uso da visão indireta e o 
posicionamento do paciente na cadeira odontológica foram reveladas como dificuldade por grande parte dos alunos. A destreza da profissão é adquirida com prática e repetição técnica, porem as posturas ergonômicas não refinam durante a profissão, pelo contrário, devido ao comodismo, favorece o surgimento de lesões ocupacionais ${ }^{20}$. Assim, constatou-se que os alunos necessitam de melhor orientação quanto á aplicação das exigências ergonômicas durante o atendimento, e que quanto mais precoce forem instalados, maiores serão os benefícios e incorporação de postura de trabalho adequadas. É necessária também uma ampla reforma que abrange todos setores do sistema odontológico para que a aplicação da ergonomia na Odontologia se torne efetiva9.

\section{- Distúrbios osteomusculares relacionados ao} trabalho

A consequência mais comum do risco do tipo ergonômico são as desordens musculoesqueléticas, conhecidas como lesões por esforços repetitivos (LER) ou distúrbios osteomusculares relacionados ao trabalho (DORT), que são doenças multifatoriais (de fatores biomecânicos, psicossociais e organizacionais) e multidimensionais (individual, grupal e social) caracterizadas pelo desgaste de estruturas do sistema musculoesquelético, sobrecarregando nervos, músculos e tendões. Atingem principalmente os punhos, mãos, pescoço, coluna, membros superiores e extremidades superiores. Tais sintomas são encontrados com maior frequência entre os Cirurgiões-Dentistas em relação a população geral e outros profissionais da saúde $\mathrm{de}^{9,18}$.

Esses distúrbios podem acarretar sequelas irreversíveis nos trabalhadores, até invalidez permanente, sendo a segunda maior causa de aposentadoria por invalidez. O estresse é relacionado a despesas previdenciárias, custo organizacional pela recolocação de funcionários, além da redução da lucratividade e da qualidade nos serviços. sofrimento psíquico e insatisfação com o trabalho, afetando a capacidade de sentir prazer e a qualidade de vida ${ }^{19}$.

Fatores causadores do desenvolvimento das desordens musculoesqueléticas estão relacionadas com o local e organização do trabalho, desenho do instrumental e técnicas clínicas, em conjunto com fatores psicossociais e estresse. Tais fatores ocorrem devido ao estresse repetitivo, levando em conta o número das repetições, postura, aplicação da força e vibração. A postura tem origem interna e externa da tarefa, sendo os internos relacionados ao indivíduo através de sua experiência, formação, estado funcional físico e sensorial, e os externos relacionados a seu quadro temporal, técnico e organizacional e a tarefa propriamente dita ${ }^{21}$.

$\mathrm{O}$ desconhecimento quanto à postura correta, sedentarismo, longas jornadas de trabalho e realização de movimentos repetitivos leva os profissionais a maiores riscos de desenvolver algum tipo de desordem osteomuscular. Quando há sintomatologia dolorosa advinda das desordens é devido a inflamação ou degeneração que atingem os Cirurgiões-Dentistas principalmente a coluna cervical e lombar, ombros, punhos e mãos, braços ${ }^{17}$.

O diagnóstico das lesões por esforço repetitivo decorre de um quadro de queixa com dor intensa, mesmo que não sejam encontradas as lesões correspondentes no exame. Toda dor, psicológica ou física, deve ser considerada real e legítima, sabendo que ambas podem estar relacionadas, uma vez que a dor física pode provocar impacto na dimensão psicológica, que agrava o quadro da dor, assim como dor de origem psicológica pode impactar na física, agravando a situação ${ }^{19}$.

Garbin et al. ${ }^{18}$ constataram que um trabalho ergonomicamente correto consiste em trabalhar com as costas retas e apoiadas no encosto do mocho, pés completamente apoiados sobre o solo, de modo que distribua o peso uniformemente e reduzindo a carga sobre as nádegas e região posterior das coxas, além de manter o equilíbrio. As coxas devem manter-se paralelas ao chão formando ângulo com a perna entre $90^{\circ}$ e $120^{\circ}$, sabendo que quanto maior a angulação, maior será a compressão da circulação venosa de retorno, causando desconforto e favorecendo o aparecimento de varizes nos membros inferiores. A cabeça do Cirurgião-Dentista deve estar ligeiramente inclinada para frente e para baixo, evitando a curvatura excessiva do pescoço, e a distância recomendada entre os olhos do profissional e a boca do paciente deve ser de $40 \mathrm{~cm}^{18,19}$.

A Fédération Dentaire Internacionale (FDI) estabelece uma classificação quanto á organização do posto de trabalho que define o posicionamento dos equipos odontológicos em quatro tipos básicos conforme a disposição dos itens: tipo 1 ou disposição lateral, tipo 2 ou disposição posterior, tipo 3 ou transtorácica e tipo 4 , em ordem ${ }^{17}$.

Como intervenção, é recomendado o trabalho a quatro mãos, planejamento do ambiente físico, do trabalho, realizar alongamentos e manter uma postura adequada $^{10}$. Destaca-se também a importância da realização de exercícios físicos, da participação ativa dos trabalhadores no planejamento para a percepção do problema e identificação dos fatores de risco para poder reconhecer as possíveis soluções e implementação de comportamentos mais adequados à promoção da saúde ${ }^{21}$.

O tratamento conservador destes distúrbios envolve fisioterapia, afastamento do profissional da atividade de repetitivo, massagem, uso de medicação analgésica e anti-inflamatória, orientações preventivas e gerais sobre a organização do trabalho e repouso. Não se pode determinar o prazo médio para cura da doença, já que depende da resposta individual ao tratamento, que deve ser feito com uma 
equipe multidisciplinar e de modo intensivo, para que o problema não se torne crônico ${ }^{18,21}$.

\section{CONCLUSÃO}

Os principais riscos ocupacionais aos quais os Cirurgiões-Dentistas estão expostos são os relacionados aos agentes: biológicos (exposição a microrganismos infectocontagiosos), físicos (ruído, radiação e iluminação), químicos (exposição a produtos químicos e mercúrio), e os ergonômicos (devido a posturas inadequadas e movimentos repetitivos). (respondendo aos objetivos específicos)

Observou-se a importância da organização do trabalho no consultório odontológico para a obtenção de melhor qualidade de vida profissional, bem como aumento na produtividade. É necessário haver condições adequadas de trabalho que possibilitem melhor desempenho, assegurando saúde física e mental. Diante disso, frisou-se a relevância do uso de EPIs, biossegurança, ergonomia e delegação de tarefas, objetivando adequar o ritmo do trabalho para que não haja efeitos negativos no dia a dia do profissional. (respondendo aos objetivos específicos)

Ainda há lacunas a serem preenchidas quanto ao conhecimento dos riscos ocupacionais do Cirurgião-Dentista, porém apurou-se serem inúmeros os fatores de risco à saúde envolvidos na prática Odontológica, sendo esta uma profissão que expõe seus trabalhadores a todos tipos de riscos ocupacionais. Há necessidade de educar e conscientizar graduandos e profissionais formados para que possam prevenir acidentes de trabalho e prolongar a atividade laboral do profissional.

\section{REFERÊNCIAS}

1. Gonçalves M, Oliveira M, Carvalho C. Riscos ocupacionais e agravos à saúde do trabalhador na prática odontológica. Rev CROMG. 2009;10(3):155-60.

2. De Carli BMG, De Carli JP, Silva SO, Linden MSS, Trentin MS, Medeiros UV. Doenças ocupacionais com manifestações bucais. Odonto. 2012;20(40):49-55.

3. Martins RJ, Garbin CAS, Garbin AJI, Prieto AKCP. Conhecimento e atitudes de profissionais da saúde frente à exposição ocupacional a material biológico. Cienc Trab. 2011;13(40):113-15.

4. Oliveira LQ, Ferreira MBDC. Ergonomia na prática odontológica. J Oral Investig. 2017;6(1):15-28.

5. Garbin AJÍ, Soares GB, Arcieri RM, Garbin CAS, Siqueira CE. Musculoskeletal disorders and perception of working conditions: a survey of brazilian dentists in São Paulo. Int J Occup Med Environ Health. 2017;30(3):367-77.

6. Silva FAG, Miasato JM. Hepatites virais: um fator de risco na prática odontológica. Rev Bras Odontol. 2009;(7):23-7.
7. Fernandez CS, Mello EB, Alencar MJS, Albrecht N. Conhecimento dos dentistas sobre contaminação das hepatites $\mathrm{B}$ e $\mathrm{C}$ na rotina odontológica. Rev Bras Odontol. 2013; 70(2):192-95.

8. Arpone RM, Teixeira ACD, Sitolino CT, Parizi JLS, Nai GA. Riscos ocupacionais químicos no conhecimento de cirurgiões dentistas. Colloq Vitae. 2012;4(1):38-52.

9. Garbin AJI, Wakayama B, Saliba NFF, Saliba TA, Garbin CAS. Ergonomia e desconforto físico: uma abordagem entre os acadêmicos em odontologia. Braz J Surg Clin Res. 2018; 21(1):29-32.

10. Moura LKB, Moura MEB, Sousa CMM, Mesquita GV, Tapety FI, Araujo TME. O conhecimento cotidiano do risco ocupacional. Rev Interdiscip NOVAFAPI. 2011;4(3):31-7.

11. Bragança DPP, Fernandes MM, Sassi C, Francesquini Júnior L, Daruge Júnior E. Condutas do Cirurgião-Dentista Frente a Acidentes Biológicos. Odonto. 2010;18(35):37-44.

12. Orestes-Cardoso SM, Farias ABL, Pereira MRMG, Orestes-Cardoso AJ, Cunha Júnior IF. Acidentes perfurocortantes: prevalência e medidas profiláticas em alunos de odontologia. Rev Bras Saúde Ocup. 2009;34(119):6-14.

13. Guo H, Zhou Y, Liu X, Tan J. The impact of the COVID-19 epidemic on the utilization of emergency dental services [published online ahead of print, 2020 Mar 16]. J Dent Sci. 2020;10.1016/j.jds.2020.02.002.

14. Sabino-Silva R, Jardim ACG, Siqueira WL. Coronavirus COVID-19 impacts to dentistry and potential salivary diagnosis. Clin Oral Investig. 2020;24(4):1619-21.

15. Ather A, Patel B, Ruparel NB, Diogenes A, Hargreaves KM. Coronavirus Disease 19 (COVID-19): implications for clinical dental care. J Endod. 2020;46(5):584-95.

16. Ministério do Trabalho e Emprego (BR). Norma Regulamentadora $\mathrm{n}^{\circ}$ 9, de 8 de junho de 1978. NR7 Programa de Controle Médico de Saúde Ocupacional. Diário Oficial União 1978 jul. 8 [acesso: 2020 jan. 17]. Disponível em: http://www.trtsp.jus.br/geral/tribunal2/LEGIS/CL T/NRs/NR_9.html

17. Miyada S, Garbin AJÍ, Gatto RCJ, Garbin CAS. Treatment adherence in patients living with HIV/AIDS assisted at a specialized facility in Brazil. Rev Soc Bras Med Trop. 2017;50(5):607-12.

18. Garbin AJI, Garbin CAS, Diniz DG. Normas e diretrizes ergonômicas em odontologia: o caminho para a adoção de uma postura de trabalho saudável. Rev Odontol Univ Cid São Paulo. 2009;21(2):155-61.

19. Santos RR, Garbin CAS, Saliba TA, Gatto RCJ, Garbin AJI. Incapacidade gerada pela dor 
osteomuscular em aluno de odontologia. Arch Health Invest. 2018;7(9):369-74.

20. Yarid SD, Diniz DG, Orenha ES, Arcieri RM, Garbin AJI. Application of ergonomics principles in dental care. Interbio. 2009;3(2):11-7.

21. Moraes PWT, Bastos AVB. As LER/DORT e os fatores psicossociais. Arq Bras Psicol. 2013;65(1):2-20.

\section{CONFLITO DE INTERESSES}

Os autores declaram não haver conflitos de interesse.

\section{AUTOR PARA CORRESPONDÊNCIA}

\section{Erika Tamy Almeida Takeuti}

Avenida José Ferreira Baptista, nº 2050, casa 30

Jardim Ipanema

16052-280 Araçatuba - SP, Brasil

erikatamyalmeida@hotmail.com

Submetido em 15/05/2020

Aceito em 02/07/2020 